\title{
E. coli Inactivation Kinetics Modeling in a Taylor-Couette UV Disinfection Reactor
}

\author{
M. L. Palacios-Contreras, ${ }^{1}$ F. Z. Sierra-Espinosa $\mathbb{D}^{2},{ }^{2}$ K. Juárez, ${ }^{3}$ S. Silva-Martínez $\mathbb{D},{ }^{2}$ \\ A. Alvarez-Gallegos $\mathbb{D}^{2}{ }^{2}$ and $M$. L. Alvarez-Benítez $\mathbb{D}^{1}$ \\ ${ }^{1}$ Posgrado en Ingeniería y Ciencias Aplicadas, Universidad Autónoma del Estado de Morelos, Av. Universidad 1001, \\ Campus Chamilpa, 62209 Cuernavaca, Morelos, Mexico \\ ${ }^{2}$ Centro de Investigación en Ingeniería y Ciencias Aplicadas, Universidad Autónoma del Estado de Morelos, Av. Universidad 1001, \\ Campus Chamilpa, Cuernavaca, Morelos 62209, Mexico \\ ${ }^{3}$ Instituto de Biotecnología, UNAM, Av. Universidad 1001, Campus Morelos, 62209, Mexico
}

Correspondence should be addressed to A. Alvarez-Gallegos; aalvarez@uaem.mx and M. L. Alvarez-Benítez; maria.alvarez@uaem.mx

Received 6 October 2019; Accepted 28 December 2019; Published 3 February 2020

Academic Editor: Joaquim Carneiro

Copyright $\odot 2020$ M. L. Palacios-Contreras et al. This is an open access article distributed under the Creative Commons Attribution License, which permits unrestricted use, distribution, and reproduction in any medium, provided the original work is properly cited.

\begin{abstract}
A simple model was developed to predict the survival behavior of E. coli subjected to UV disinfection in a Taylor-Couette reactor. The model includes the CFD evaluation of the counterrotating toroidal vortices developed within the annular space of two coaxial cylinders. The UV lamp was located within the diameter of the internal rotating cylinder. The residence time of the bacteria near the UV lamp is, therefore, a function of both the size of the vortex and its angular velocity. The effect of angular velocity on the formation of counterrotating toroidal vortices and their impact on the kinetics of UV microbial inactivation was experimentally evaluated. The kinetics of microbial inactivation follow an apparent first-order kinetic equation between 300 and 2000 revolutions per minute. Therefore, in this range of angular velocities, a set of $k$ values (indirectly taking into account the hydrodynamic pattern and UV irradiance) was obtained for a given concentration of bacteria. Then, the set of $k$ values was correlated with the range of angular velocities applied using the polynomial equation. A $k$ value can be obtained for an unknown angular velocity through the polynomial equation. Therefore, a simulation curve of microbial inactivation can be obtained from the first-order kinetic equation. The efficiency of bacteria removal improves depending on the angular velocity applied. A good agreement is observed between the simulation of the survival behavior of the microorganisms subjected to UV disinfection with the experimental data.
\end{abstract}

\section{Introduction}

In recent years, UV light exposure has been recognized as one of the best available options for water treatment $[1,2]$. However, the design of a reliable UV disinfection system should take into account several factors $[3,4]$, such as germicidal effect, sensor, water quality, UV reflection, and divergence. The microbial inactivation prediction is a useful tool because it provides guidance to assess the efficiency of UV disinfection systems. The survival behavior of microorganisms subjected to UV disinfection may obey different kinetic models [4-9]. However, for a long time, it was documented that, under certain experimental conditions, the survival behavior of the microorganisms subjected to UV disinfection may obey a simple exponential curve [10]. Indeed, in the absence of shoulder effects or in the case that they can be ignored, the UV inactivation of microorganisms can be fitted to a first-order decay rate $[4,8,11]$ :

$$
\log \left(N_{t} / N\right)=-k U_{\text {dose }}
$$

where $N$ is the initial microbial concentration, $N_{t}$ is the microbial concentration after contact time $t, \mathrm{UV}_{\text {dose }}$ is 
the fluence $\left(\mathrm{mW} \mathrm{scm}^{-2}\right)$, and $k$ is the inactivation rate constant $\left(\mathrm{cm}^{2} \mathrm{~mW}^{-1} \mathrm{~s}^{-1}\right)$. However, if some deviation from the exponential law is noticed, UV inactivation of microorganisms must be interpreted by a more complex inactivation kinetics model [6,12-14]. Although equation (1) looks simple, the prediction/modeling of a practical microorganism inactivation behavior based in such equation is a challenging task. Indeed, the parameter $\mathrm{UV}_{\text {dose }}$ may be defined as

$$
\mathrm{UV}_{\text {dose }}=\frac{\mathrm{UV}_{\text {flux }} t}{\text { radiating surface }},
$$

where $\mathrm{UV}_{\text {flux }}$ is the radiant power (W), $t$ is the exposure time (s), and radiating surface is in $\mathrm{cm}^{2}$. Although some protocols for determining the $\mathrm{UV}_{\text {dose }}$ were developed for low-pressure mercury vapor lamps (LP UV) [3, 15-17], it is difficult to select a $U_{\text {dose }}$ value that can inactivate a given microorganism under different experimental conditions. Indeed, the presence of a set of attenuation/expansion factors affects exposure time and $\mathrm{UV}_{\text {flux }}$; therefore, the $\mathrm{UV}_{\text {dose }}$ is affected [18]. If one of the main attenuation/expansion factors is systematically changed while the rest are kept constant, its contribution to the UV inactivation process can be evaluated by the inactivation rate constant $(k)$. Indeed, this parameter can be evaluated from experimental data and its interpretation is strongly related to the sensitivity of microorganisms to the $\mathrm{UV}_{\text {dose }}$. The best set of experimental conditions during UV disinfection can be identified taking into account the numerical value of $k$. Surely, a high $k$ value is always associated to one or more good combinations of the components of equation (2). This criterion can be illustrated by a couple of examples: Firstly, the inactivation profiles of four different microbial species were obtained at the same wavelength as a function of the UV-LED exposure time. It was found that $E$. coli was the more sensitive species because its $k$ was the highest obtained value [19]. Secondly, it was found that $k$ (evaluated from fluence inactivation response of $B$. subtilis spores) is not altered by the flow rate (10.8 to $\left.7.8 \mathrm{~mL} \mathrm{~min}^{-1}\right)$. However, the $k$ value increased when the disinfection experiment was repeated in a static test [20]. In the absence of shoulder effects, the kinetics of microbial inactivation is a function of $\mathrm{UV}_{\mathrm{dose}}$ and it might be described by equation (1). However, due to the set of attenuation/expansion factors, such equation fails to describe the experimental inactivation of microorganisms during UV irradiation. Such phenomenon has been noticed for a long time. As an example, it can be mentioned that a commercial UV water purifier was used to inactivate E. coli (obeying an apparent first-order decay rate) at different flow rates [21]. The highest percent kill was achieved at the lowest flow rate $\left(0.03 \mathrm{~mL} \mathrm{~min}^{-1}\right)$. However, if the fluid pattern is modified to force all water closer to the UV lamp, the percent kill at the fastest flow rate $\left(1.92 \mathrm{~mL} \mathrm{~min}^{-1}\right)$ was raised. Since then, it was understood that the flow field and reactor geometry are linked to the UV disinfection systems [20, 22]. Depending on the reactor design, batch/flow-through reactors may develop flow conditions, at low or high flow rates, leading to water volumes of lower UV radiation. Additionally, the spatial distribution of microorganism concentration is also linked to the fluid pattern. A proper simulation/prediction of the $\mathrm{UV}_{\text {dose }}$ implies the combination/integration of several models that describe the fluence rate, flow pattern, and kinetics of microbial inactivation.

During the past decades, several models have been developed to predict UV disinfection systems, and such models evolved from a fairly limited approach to models that globally include complex UV systems. In the first case, a model was used to predict the radiation intensity field [23] and another model was focused on the inactivation behavior of microorganisms [24] in UV reactors; similarly, using computational fluid dynamics (CFD), a radiation model was developed to improve the fluence rate distribution in an annular $\mathrm{UV}$ reactor [25]. In the second case, two or more models were combined to simulate a more complex UV microbial inactivation. Under this approach, experimental radiation profile data were used to derive a radiation distribution model. This model was then combined with the CFD software to predict the fluence rate distribution within the reactor [26]. In fact, when the prediction of UV microbial inactivation includes the hydrodynamics of the UV reactor, CFD is a powerful tool for describing the fluid pattern. The simulation of UV disinfection in an open channel configuration [27] was performed using a combination of four mathematical models (hydrodynamic pattern, intensity field, dose distribution, and inactivation kinetics) fed with several experimental data sets (collimated beam, Doppler laser velocimetry, UV transmittance, and UV output power). The design of the UV reactor (including the water inlet/outlet) and the position and distribution of the UV lamps located inside the reactor modify the fluid pattern and can be described by CFD $[28,29]$. Therefore, the $\mathrm{UV}_{\text {dose }}$ within a reactor depends largely on the accuracy to numerically describe the turbulent structures developed based on the geometry of the UV reactor [30-33]. With the growing technique of LP UV disinfection for water treatment, the interest of modeling and after predicting the inactivation behavior of microorganism is justified.

The aim of this work is to improve and predict the kinetics of microbial inactivation by the LP UV disinfection technique. The survival behavior of the microorganisms subjected to UV disinfection in a Taylor-Couette reactor is systematically studied according to the fluid pattern. The set of experimental results obtained are used to develop a simple model (using a minimum number of parameters) that combines the kinetics of microbial inactivation (equation (1)) with the numerical description of the fluid pattern to predict the experimental inactivation kinetics of $E$. coli in a Taylor-Couette UV disinfection reactor. However, the microbial inactivation kinetics model and the numerical description of the fluid pattern model are carried out separately, which provides a simple model to predict UV disinfection. This approach offers greater flexibility for discussions of results and interpretations. The simulated UV response kinetics in E. coli based on its concentration and the hydrodynamic pattern when a Taylor-Couette vortex was absent and then formed, are included in this work. In both cases (Taylor 


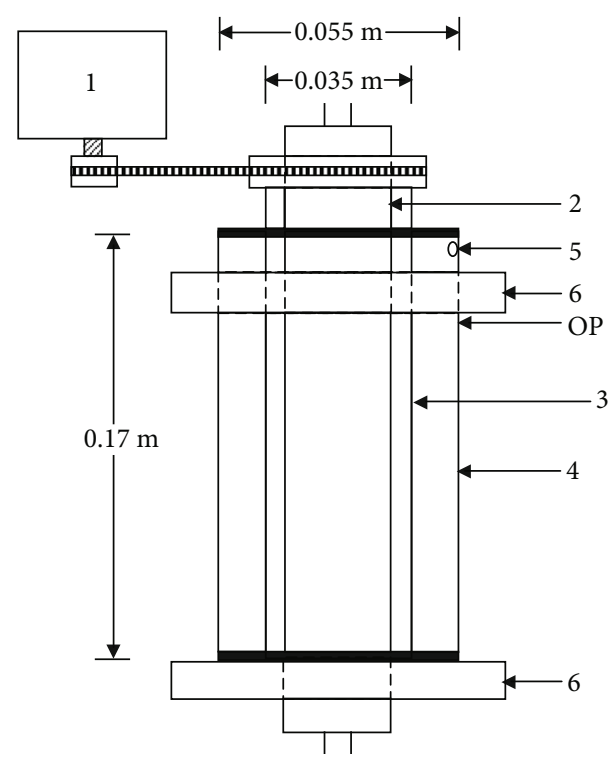

Figure 1: Scheme of the experimental configuration of the TaylorCouette vortex reactor. (1) Motor, (2) LP UV lamp, (3) inner (rotating) cylinder, (4) outer (fixed) cylinder, (5) sample point, and (6) supports. OP: observation point.

vortex is present/absent), the simulation of UV disinfection showed good agreement with the experimental results.

\section{Materials and Methods}

2.1. Specifications of the UV Disinfection Reactor. A schematic configuration of the Taylor-Couette UV disinfection reactor is depicted in Figure 1. Both cylinders were made of Pyrex glass with the same length $(17 \mathrm{~cm})$. The inner radius of the outer cylinder was $2.75 \mathrm{~cm}$, while the external radius of the inner cylinder was $1.75 \mathrm{~cm}$. The inner cylinder was driven through a belt by a stepping motor (Siemens, $0.373 \mathrm{~kW}, 60 \mathrm{~Hz}, 220 / 440 \mathrm{~V}$, and $1.80 / 0.90 \mathrm{~A}$ ). The cylinderrotation rates, measured with a frequency counter, were stable and accurate up to the maximum value used, $2500 \mathrm{rev}$ olutions per minute. The reactor sample point/inlet was located at the top of the external cylinder. The low-pressure mercury lamp (G15T8, Tecnolite, $254 \mathrm{~nm}, 15 \mathrm{~W}, 40 \mathrm{~cm}$ length) was located inside the diameter of the inner cylinder.

\subsection{Cultivation and Enumeration of Bacteria. E. coli (XL-1} Blue) was chosen as the microorganism model, and its culture was carried out in a Luria-Bertani medium under anaerobic conditions at $37^{\circ} \mathrm{C}$ and 200 revolutions per minute (rpm) using an incubator. Bacterial growth was followed by spectrophotometry (model DU ${ }^{\circledR}$ 730, Beckman Coulter ${ }^{\circledR}$ ) at $600 \mathrm{~nm}$ and stopped when the optical density reached $0.2-0.3$. Subsequently, a volumetric sample $(67-45 \mathrm{~mL})$ was taken and centrifuged (model Sorvall ST 16R, Thermo Fisher Scientific) at $4000 \mathrm{rpm}$ for $8 \mathrm{~min}$ at $20^{\circ} \mathrm{C}$. The pellet was washed (using sterilized water, $\mathrm{pH} 7$ ) and then suspended in $190 \mathrm{~mL}$ of sterilized water and vigorously mixed to obtain $\sim 10^{8}$ colony-forming units $\mathrm{mL}^{-1}$. Except for the UV test, all samples were kept in the dark. Appropriated dilutions were made when necessary. For the quantification of bacteria, the samples were properly diluted and then spread on $\mathrm{LB}$ agar plates before the incubation at $37^{\circ} \mathrm{C}$ for $24 \mathrm{~h}$. Subsequently, the colonies were counted.

2.3. Fluid Dynamics Modelling. The numerical description of the fluid pattern inside the Taylor-Couette UV disinfection reactor was performed by a commercial CFD package (Fluent, Ansys version 15) based on a finite volume method. The fluid flow can be described considering the conservation of mass, momentum, and energy. However, considering some practical restrictions, the fluid pattern can be described simply by simultaneously solving mass and momentum conservation equations, as described in more detail elsewhere [34]. The stagnant fluid contained between two coaxial cylinders generates a set of counterrotating vortices in the annular gap when the inner cylinder rotates. The effects of this turbulence can be further described by turbulence models that can be solved alongside the set of mass and momentum conservation equations. Nowadays, CFD packages include a set of turbulent models to better describe a turbulent fluid flow. The selection of the best turbulence model depends on the nature of the hydrodynamic problem to be solved, the level of accuracy required, and user expertise [30]. In this work, the normalization-group model (RNG) was selected to describe the development of the fluid pattern as a function of the rotating speed of the internal cylinder. The accuracy of the numerical solution depends on the cell number (thin or rough grid) of the computational domain (the reactor annular gap). Several simulations were performed to find out the grid dependency of the results. A set of four different cell numbers $\left(2.5 \times 10^{5}, 5 \times 10^{5}, 1.0 \times 10^{6}\right.$, and $\left.1.5 \times 10^{6}\right)$ were investigated. Finally, the computational domain is discretized in 505,164 hexahedral cells (the convergence index of the grid was $0.205 \%$ ) in whose center the equations are solved. Once the boundary conditions for a particular cell center are established, the solution is applied to the cell boundaries by interpolation. The information obtained is used to advance stepwise to the neighboring cell until the entire domain is covered. The boundary conditions were defined as inlet conditions according to the inner cylinder rotating velocity $(0,300,600,1200$, and $2000 \mathrm{rpm})$ and the physical properties of the fluid (density: $998.2 \mathrm{~kg} \mathrm{~m}^{-3}$; cinematic viscosity: $1.01 \times 10^{-6} \mathrm{~m}^{2} \mathrm{~s}^{-1}$; dynamic viscosity: $0.001 \mathrm{~kg} \mathrm{~m}^{-1} \mathrm{~s}^{-1}$; and temperature: $25^{\circ} \mathrm{C}$ ).

2.4. Modeling of Survival Curves. In our approach, microorganisms were considered as soluble species reacting; therefore, they are transported in the UV reactor throughout a spatial distribution described by the fluid velocity profile (Eulerian approach) $[35,36]$. The parameters that were not directly evaluated in this work are UV intensity, UV fluence rate, UV fluence received by particles, and reflective and diffuse fraction of the Pyrex glass walls. All of them were taken as unknown constant values. However, their important contribution to the UV microbial inactivation kinetics was experimentally evaluated by the inactivation rate constant. Except in the first 100 minutes, the microbial inactivation kinetics follows an apparent first-order kinetic equation and 
can be adjusted to equation (1). In this model, $N$ is a constant but does not represent the initial microbial concentration (such constant has no physical meaning in the studied experimentation). However, the rest of the parameters in equation (1) kept the same meaning described before. All the experiments were repeated three times and then averaged. For a given bacteria concentration, four microbial inactivation curves $\left(\log \left(N_{t} / N\right)\right.$ vs. exposure time) were obtained in the Taylor-Couette UV disinfection reactor, as a function of the Taylor number (Ta). From each microbial inactivation curve, a pair of $N$ and $k$ values were obtained. For a given bacteria concentration, $k$ values can be correlated to the Ta number (the hydrodynamic pattern describing the Taylor-Couette vortex) expressed as a polynomial equation. Inside of the experimental conditions studied, a $k$ value can be obtained for an unknown Ta number by the polynomial equation. Therefore, a microbial inactivation simulation curve can be obtained when time starts to increase in equation (1). Similar correlations were used to develop simple chemical models for predicting wastewater treatment [37-39].

\section{Results and Discussion}

3.1. Numerical Description of Taylor-Couette Vortex. The fluid contained in the annular gap of two coaxial cylinders presents instability when the inner cylinder rotates. Instability produces a series of counterrotating vortices throughout the annular gap. The vortices move the flow of the fluid into and out of the best-lit region of the reactor, creating a highly effective radial mixing within the Taylor-Couette vortex. Between vortices, the hydraulic boundaries form a mass transfer barrier that minimizes the exchange of fluid elements between them [40] and improves the kinetics of microbial inactivation, which is one of the objectives of this work.

The residence time of the bacteria near the UV lamp is, therefore, a function of both, the vortex size and its angular velocity (mainly, axial linear velocities, $y$-direction and radial linear velocities, and $x$-direction). Without axial flow, the fluid pattern is a function of the Ta number defined as follows [40-42]:

$$
\mathrm{Ta}=\frac{r_{\mathrm{i}} \omega_{\mathrm{i}} d}{v}\left[\frac{d}{r_{\mathrm{i}}}\right]^{1 / 2},
$$

where $r_{\mathrm{i}}$ is the inner cylinder radius $(\mathrm{cm}), d$ is the gap width between two concentric cylinders $(\mathrm{cm}), \omega_{\mathrm{i}}$ is the angular velocity of the inner cylinder $\left(\mathrm{s}^{-1}\right)$, and $v$ is the kinematic viscosity $\left(\mathrm{cm}^{2} \mathrm{~s}^{-1}\right)$.

When the Ta number exceeds a critical value, $\mathrm{Ta}_{\mathrm{C}}$ (this numerical value depends on $d / r_{i}$ ), the counterrotating toroidal vortices along the cylinder axis develop, describing five modes of flow along the annular gap $[41,42]$ :

(1) Laminar flow $\mathrm{Ta}<\mathrm{Ta}_{\mathrm{C}}$

(2) Laminar vortex (individually periodic) flow $\mathrm{Ta}_{\mathrm{C}}<$ $\mathrm{Ta}<800$

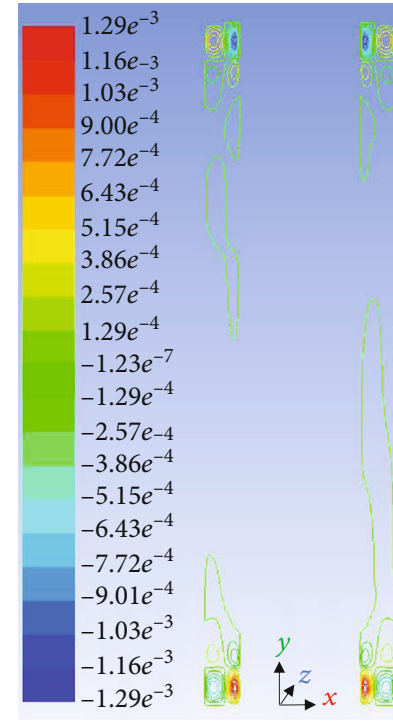

(a)

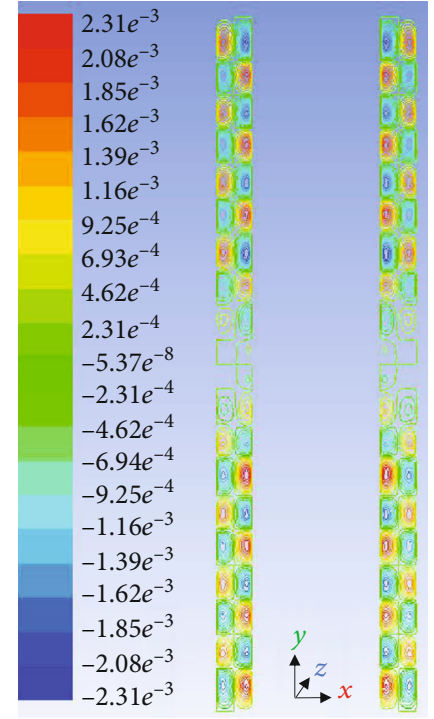

(b)
FIgURE 2: Formation of rotating toroidal vortices in the reactor length, as a function of angular velocities. (a) At $9.55 \mathrm{rpm}$, a couple of vortices formed at both extremes. (b) At $9.65 \mathrm{rpm}, 8$ vortices formed in each extreme (up and bottom). At the reactor center, a weak formation of 4 more vortices developed.

(3) Transition (double-periodic) flow $800<\mathrm{Ta}<2000$

(4) Turbulent vortex flow $2000<\mathrm{Ta}<10,000-15,000$

(5) Turbulent flow Ta $>15,000$

The numerical description of the fluid instability was performed at 8 different Ta numbers $(131,132,191,1309,4116$, 8231,16462 , and 27437) to visualize the formation/development of the counterrotating toroidal vortices within the annular space, for the same reactor configuration used in the experimental study. Figures 2, 3, 4, 5, and 6 show the evolution of the vortices. At the lowest angular velocity ( $9.55 \mathrm{rpm}, \mathrm{Ta}=131)$, the fluid is already unstable, but only a pair of rotating toroidal vortices formed at both ends of the reactor length, in the annular space. The maximum averaged linear velocity was evaluated as $1.17 \times 10^{-3} \mathrm{~m} \mathrm{~s}^{-1}$. When the angular velocity increases slightly $(9.65 \mathrm{rpm}, \mathrm{Ta}=132), 8$ counterrotating toroidal vortices formed well at each end (top and bottom) of the reactor length, in the annular gap. In the center of the reactor, a weak formation of 4 more vortices was developing (Figure 2). The maximum averaged linear velocity was evaluated as $2.31 \times 10^{-3} \mathrm{~m} \mathrm{~s}^{-1}$. For the purpose of this work, these two angular velocities are not interesting. However, for $13.95 \mathrm{rpm}(\mathrm{Ta}=191) 20$ counterrotating toroidal vortices were well formed.

The maximum average linear velocity was evaluated as $3.4 \times 10^{-3} \mathrm{~m} \mathrm{~s}^{-1}$ (Figure 3 ). As the angular velocity gradually increases, the resulting toroidal vortices increase in both size and linear velocity. As Ta increases, a smaller number of counterrotating toroidal vortices formed along the length of the reactor, in the annular gap. For the angular velocity of $95.5 \mathrm{rpm}(\mathrm{Ta}=1309), 18$ vortices were well formed with 


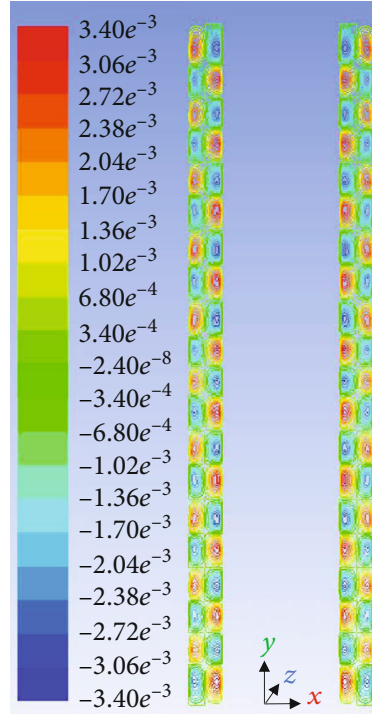

(a)

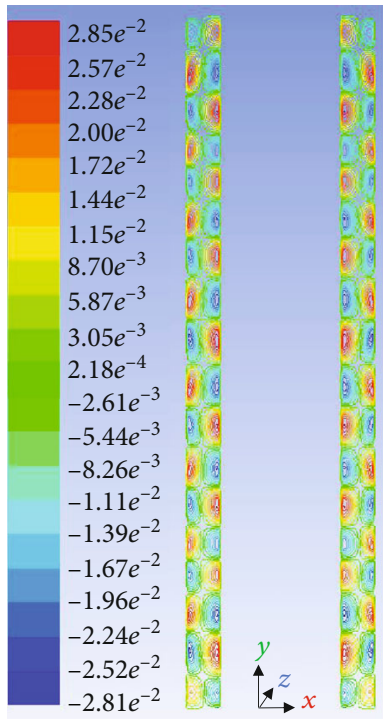

(b)

FIGURE 3: As the angular velocity gradually increases, the resulting toroidal vortices increased in both size and linear velocity. (a) At $13.95 \mathrm{rpm}, 20$ vortices formed. (b) At $95.5 \mathrm{rpm}, 18$ vortices formed.

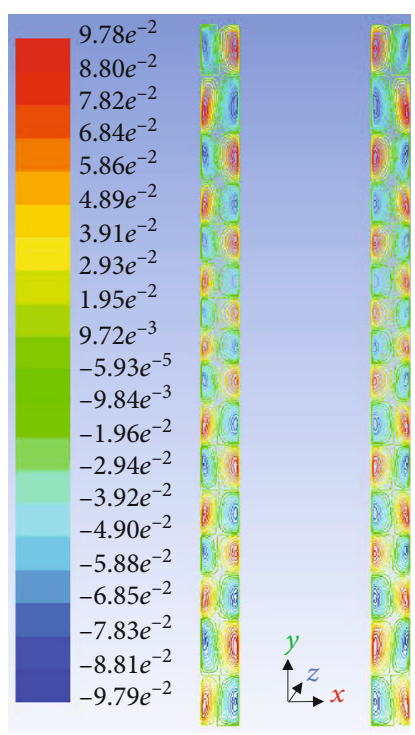

(a)

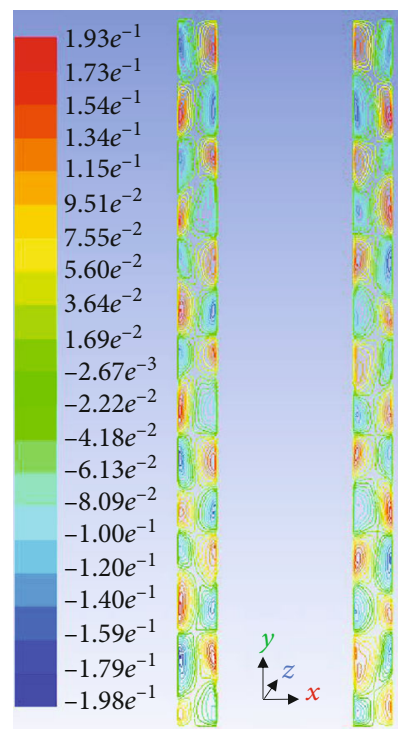

(b)
FIGURE 4: Formation of rotating toroidal vortices in the reactor length, as a function of angular velocities. (a) At $300 \mathrm{rpm}, 16$ vortices were formed. (b) At $600 \mathrm{rpm}, 14$ vortices were formed.

a maximum average linear velocity of $2.85 \times 10^{-2} \mathrm{~m} \mathrm{~s}^{-1}$ (Figure 3). Following the same trend, for $300 \mathrm{rpm}$ $(\mathrm{Ta}=4116)$ and $600 \mathrm{rpm}(\mathrm{Ta}=8231), 16$ and 14 vortices were formed, respectively.

Following the same order, the maximum average linear velocities were evaluated as $9.3 \times 10^{-2} \mathrm{~m} \mathrm{~s}^{-1}$ and $1.64 \times$ $10^{-1} \mathrm{~m} \mathrm{~s}^{-1}$, respectively (Figure 4). Finally, for the last two higher angular velocities at $1200 \mathrm{rpm}(\mathrm{Ta}=16,462)$ and $2000 \mathrm{rpm}(\mathrm{Ta}=27,437)$, the rotating toroidal vortex number

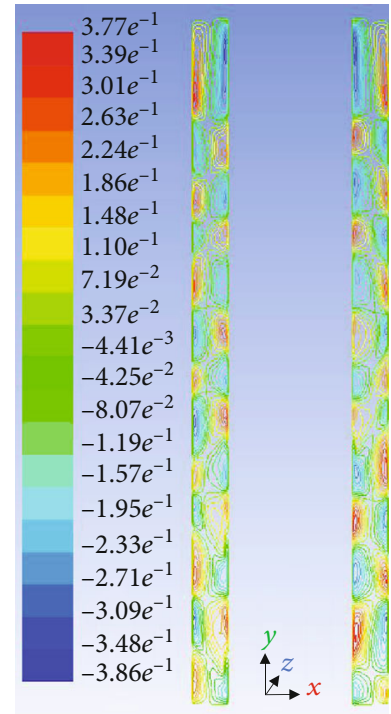

(a)

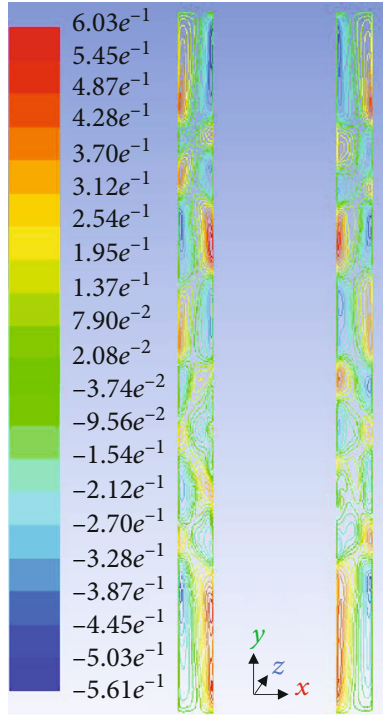

(b)
FIGURE 5: Formation of rotating toroidal vortices in the reactor length, as a function of angular velocities. (a) At $1200 \mathrm{rpm}, 13$ vortices formed. (b) At $2000 \mathrm{rpm}, 10$ vortices formed.

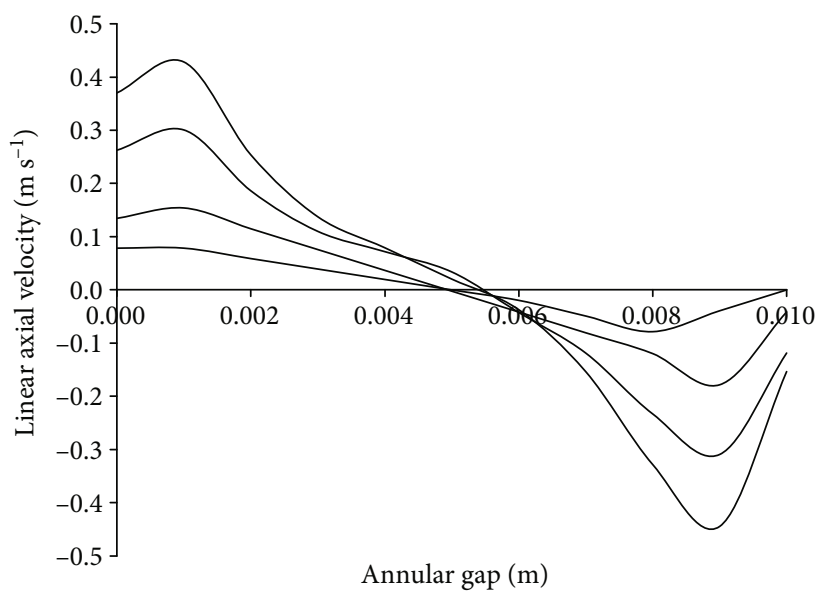

Figure 6: Axial velocity profiles at different angular velocities (at left, from bottom to top: $300,600,1200$, and $2000 \mathrm{rpm}$, respectively) evaluated in the middle of a toroidal vortex height as a function of the annular gap distance ( $x$-direction, from 0 to $0.01 \mathrm{~m}$ ).

further decreased to 13 and 10, respectively, while their maximum average linear velocities increased to $3.1 \times 10^{-1} \mathrm{~m} \mathrm{~s}^{-1}$ and $5.7 \times 10^{-1} \mathrm{~m} \mathrm{~s}^{-1}$, respectively. In addition, for the highest angular velocity studied, at the ends of the reactor length, the vortex size increased dramatically in the annular gap, while at the center of the reactor length, the toroidal shape of the vortex begins to gradually be lost in the annular gap (Figure 5). This last phenomenon can negatively impact the kinetics of microbial inactivation.

Figure 6 shows the axial velocities, evaluated in the middle of a toroidal vortex height, as a function of the annular gap distance ( $x$-direction, from 0 to $0.01 \mathrm{~m}$ ) at different angular velocities. The location of the observation point, 


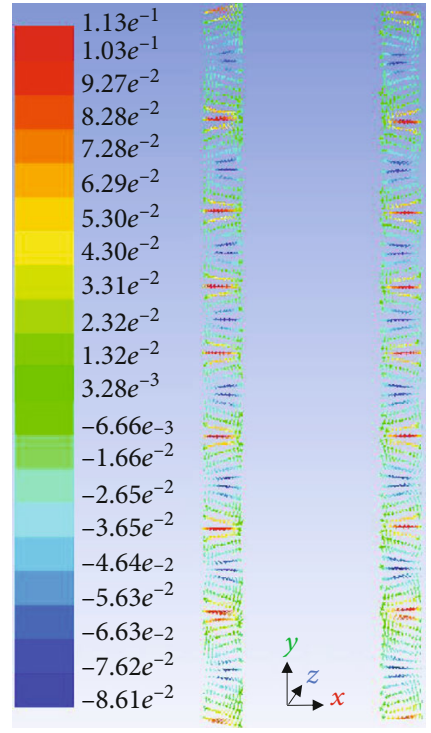

(a)

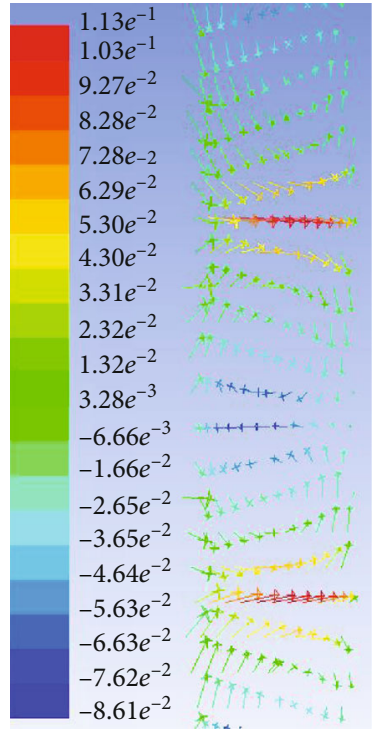

(b)
Figure 7: At $300 \mathrm{rpm}$, (a) radial velocity vectors of the 16 counterrotating toroidal vortices formed along the reactor length. (b) Some intercalated, red, jet-like flow structures emerging at high radial velocities from the inner (rotating) wall and going to the outer (fixed) wall. A mass transfer barrier between adjacent vortices formed.

OP (from which the axial velocities were numerically evaluated), was set at the top of the reactor at $0.14 \mathrm{~m}$ ( $y$-direction, Figure 1) at $300 \mathrm{rpm}$. For the last three angular velocities $(600,1200$, and $2000 \mathrm{rpm})$, the OP was located at $0.11 \mathrm{~m}$. This variation was necessary to match the middle height of the toroidal vortices. The symmetries of the numerical axial velocities obtained indicate a well-formed toroidal vortex shape. For $300 \mathrm{rpm}$, Figure 7 shows the radial velocities of the 16 counterrotating toroidal vortices formed along the length of the reactor in the annular gap.

Some intercalated red jet flow structures emerge at high radial velocities $\left(1.13 \times 10^{-1} \mathrm{~m} \mathrm{~s}^{-1}\right)$ from the inner wall (swivel) and go to the outer wall (fixed). Such a fluid pattern is found between the cells and forms a mass transfer barrier between adjacent vortices; such phenomena were observed before [43].

\subsection{Inactivation of E. coli by Taylor-Couette UV Disinfection} Reactor Treatment. The effect of angular velocity on the formation of counterrotating toroidal vortices and their impact on the kinetics of UV microbial inactivation were experimentally evaluated. It was found that, during UV irradiation, the survival behavior of microorganisms has the same removal of bacterial efficiency in the following cases: (a) when the fluid contained in the reactor annular space is immobilized and (b) when a low angular velocity $(<200 \mathrm{rpm})$ is applied. From the kinetic point of view of microbial inactivation, when the Ta number exceeds a critical value of $\mathrm{Ta}_{\mathrm{C}}$ (in this case is 2743 or $200 \mathrm{rpm}$ ), the hydrodynamic pattern has a notable impact on the kinetics of UV microbial inactivation, in the Taylor-Couette UV disinfection reactor used in this

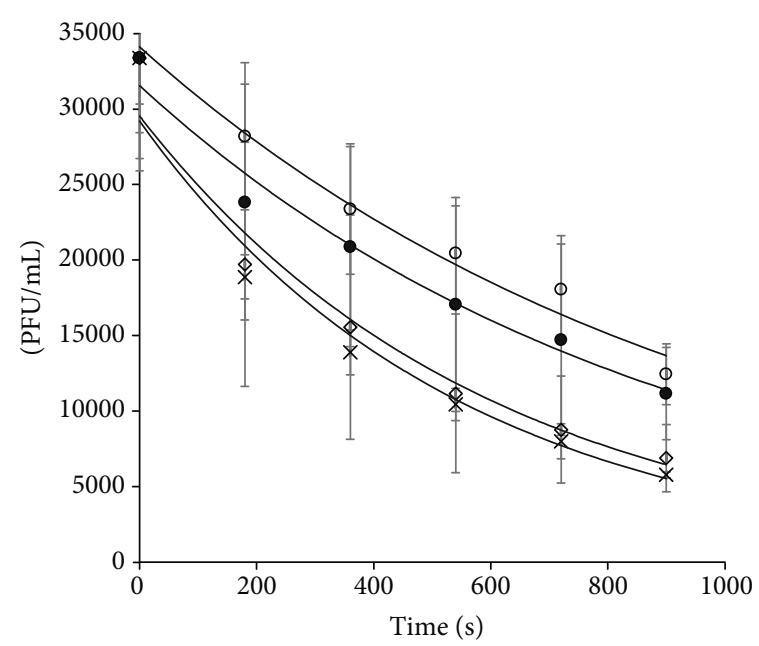

FIgURE 8: Experimental data are represented by symbols. Lines represent a tendency. For $35,000 \mathrm{PFU} \mathrm{mL}^{-1}$, four microbial inactivation curves were obtained in the UV Taylor-Couette reactor as a function of the angular velocity: $(O) 0 \mathrm{rpm}$, $300 \mathrm{rpm},(\diamond) 600 \mathrm{rpm}$, and $(\times) 2000 \mathrm{rpm}$. Except for the first 100 minutes, the microbial inactivation kinetic follows an apparent first-order kinetic equation.

work. At higher $\mathrm{Ta}_{\mathrm{C}}$ values, the removal of bacterial efficacy is improved.

The UV microbial inactivation kinetics was experimentally evaluated for three different concentrations of bacteria. For the first bacterial concentration of $35,000 \mathrm{PFU} \mathrm{mL}^{-1}$, four microbial inactivation curves were obtained in the TaylorCouette UV disinfection reactor based on the following angular velocities: 0, 300, 600, and $2000 \mathrm{rpm}$ (Figure 8). Except for the first 100 minutes, the microbial inactivation kinetics follows an apparent first-order kinetic equation and the following set of $k$ values of each microbial inactivation curve (log $\left(N_{t} / N\right)$ vs. time) was obtained: $0 \mathrm{rpm}\left(k=-4.42 \times 10^{-4} \mathrm{~s}^{-1}\right.$; $\left.R^{2}=0.9671\right), \quad 300 \mathrm{rpm} \quad\left(k=-4.91 \times 10^{-4} \mathrm{~s}^{-1} ; \quad R^{2}=0.9833\right)$, $600 \mathrm{rpm} \quad\left(k=-7.34 \times 10^{-4} \mathrm{~s}^{-1}, \quad R^{2}=0.9795\right), \quad$ and 2000 $\left(k=-8.02 \times 10^{-4} \mathrm{~s}^{-1} ; R^{2}=0.9804\right)$, as depicted in Figure 9 . Taking as reference the constant value of the inactivation rate obtained at $0 \mathrm{rpm}$, the angular velocity increases improve the kinetics of microbial inactivation.

The $k$ value gradually improves by $11 \%, 66 \%$, and $82 \%$ when the angular velocity increases by 300,600 , and $2000 \mathrm{rpm}$, respectively. Starting from $0 \mathrm{rpm}$ and following the same angular velocity sequence, the removal of bacterial efficiency $\left(Y \%=\left(N-N_{t} / N\right) \times 100\right)$ in $900 \mathrm{~s}$ was $63 \%, 67 \%$, $79 \%$, and $83 \%$, as shown in Figure 9.

For this bacterial concentration, the inactivation rate constant was correlated with $\omega$ (angular velocity, measured in $\mathrm{rpm}$ ), including the stationary fluid, by the following polynomial equation:

$$
k=-1.911(10)^{-10}(\omega)^{2}+5.795(10)^{-7}(\omega)+4.096(10)^{-4},
$$

$R^{2}=0.9073$. 


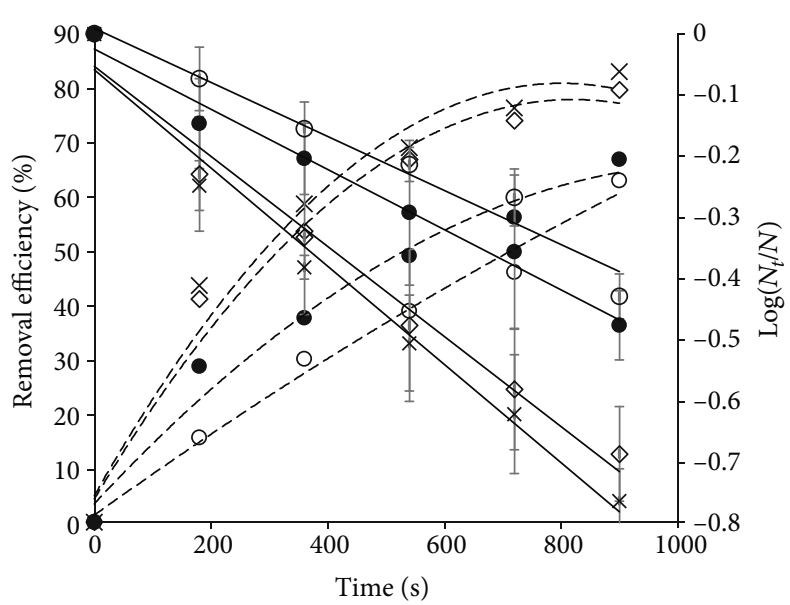

FIGURE 9: Experimental data are represented by symbols. Lines represent a tendency. For $35,000 \mathrm{PFU} \mathrm{mL}^{-1}$, at $0 \mathrm{rpm}$ the inactivation rate constant value is $k=-4.42 \times 10^{-4} \mathrm{~s}^{-1}$ and the bacteria efficiency removal was $63 \%(O)$. The $k$ value improves gradually by $11 \%, 66 \%$, and $82 \%$ when the angular velocity increases to $300 \mathrm{rpm}(\bullet), 600 \mathrm{rpm}(\diamond)$, and $2000 \mathrm{rpm}(\times)$, respectively. In the same order, the bacteria efficiency removal was $67 \%, 79 \%$, and $83 \%$.

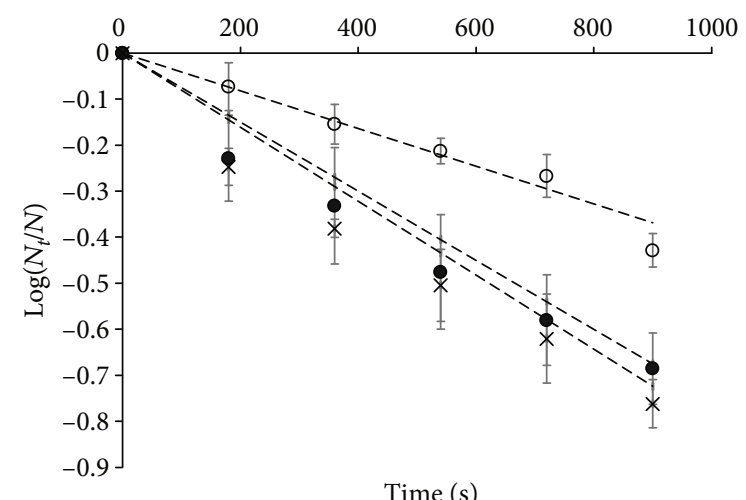

Figure 10: For 35,000 PFU mL ${ }^{-1}$, experimental data represent the UV microbial inactivation kinetics. The dashed lines represent the first $900 \mathrm{~s}$ of survival behavior simulation of microorganisms subjected to the UV irradiation process in the Taylor-Couette reactor at different angular velocities: $(\bigcirc) 0 \mathrm{rpm},(\bullet) 600 \mathrm{rpm}$, and (x) $2000 \mathrm{rpm}$.

For any arbitrary angular velocity, within the experimental conditions studied, a $k$ value can be obtained using equation (4). Therefore, a simulation curve of microbial inactivation can be obtained using equation (1). Figure 10 shows (dashed lines) the first $900 \mathrm{~s}$ of simulation of the survival behavior of microorganisms subjected to a UV irradiation process in the Taylor-Couette reactor at different angular velocities $(0,600$, and $2000 \mathrm{rpm})$. The corresponding experimental data are shown in the same figure.

For the second bacterial concentration equal to $400,000 \mathrm{PFU} \mathrm{mL}^{-1}$, five microbial inactivation curves were obtained in the Taylor-Couette UV disinfection reactor as a

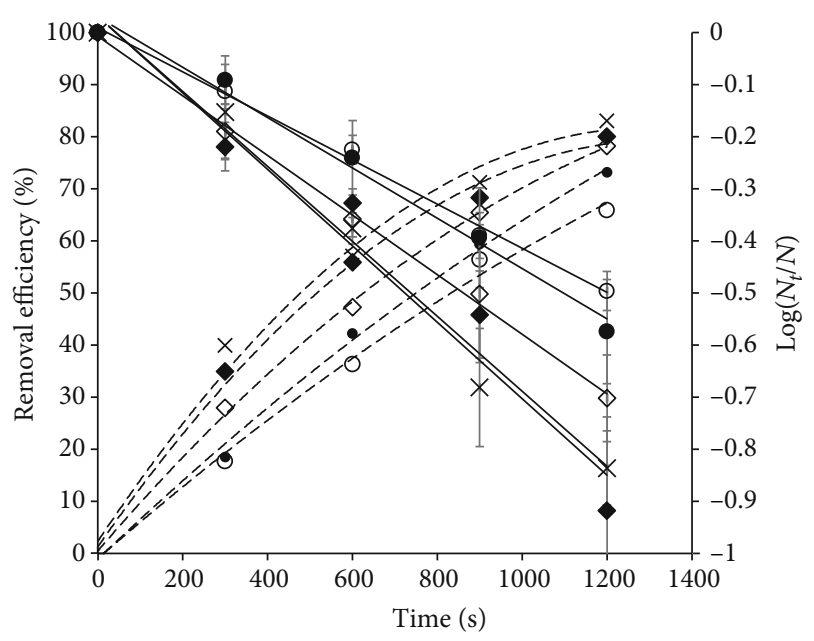

FIGURE 11: Experimental data are represented by symbols. Lines represent a tendency. For $400,000 \mathrm{PFU} \mathrm{mL}^{-1}$, at $0 \mathrm{rpm}$ the inactivation rate constant value is $k=-4.23 \times 10^{-4} \mathrm{~s}^{-1}$ and the bacteria efficiency removal was $66 \%(0)$. The $k$ value improves gradually by $14 \%, 35 \%, 70 \%$, and $73 \%$ when the angular velocity increases to $300 \mathrm{rpm}(\bullet), 600 \mathrm{rpm}(\diamond), 1200(\times)$, and $2000 \mathrm{rpm}$ $(\downarrow)$, respectively. In the same order, the bacteria efficiency removal was $73 \%, 78 \%, 80 \%$, and $83 \%$.

function of the angular velocity (Figure 11). The following set of $k$ values of each microbial inactivation curve was obtained: $0 \mathrm{rpm}\left(k=-4.23 \times 10^{-4} \mathrm{~s}^{-1} ; R^{2}=0.995\right), 300 \mathrm{rpm}$ $\left(k=-4.84 \times 10^{-4} \mathrm{~s}^{-1} ; \quad R^{2}=0.988\right), \quad 600 \mathrm{rpm} \quad(k=-5.72 \times$ $\left.10^{-4} \mathrm{~s}^{-1} ; R^{2}=0.998\right), 1200 \mathrm{rpm}\left(k=-7.19 \times 10^{-4} \mathrm{~s}^{-1} ; R^{2}=\right.$ $0.958)$, and $2000 \mathrm{rpm}\left(k=-7.34 \times 10^{-4} \mathrm{~s}^{-1} ; R^{2}=0.987\right)$. Also, in this case, the microbial inactivation kinetics is a function of angular velocity.

Taking as a reference the constant value of the inactivation rate obtained at $0 \mathrm{rpm}$, the constant of inactivation rate gradually improves by $14 \%, 35 \%, 70 \%$, and $73 \%$ when the angular velocity increases by $300,600,1200$, and $2000 \mathrm{rpm}$, respectively. Starting from $0 \mathrm{rpm}$ and following the same angular velocity sequence, the removal of bacterial efficiency in $1200 \mathrm{~s}$ was $66 \%, 73 \%, 78 \%, 80 \%$, and $83 \%$ (Figure 11 ). For this concentration of bacteria, the inactivation rate constant was correlated with $\omega$ (including the stationary fluid) by the following polynomial equation:

$$
\begin{aligned}
k & =9.418 \times 10^{-11}(\omega)^{2}+3.557 \times 10^{-7}(\omega)+0.4057, \\
R^{2} & =0.9818 .
\end{aligned}
$$

Following the same procedure as before, within the experimental conditions studied, for any angular velocity a $k$ value can be obtained from equation (5). Therefore, a simulation curve of microbial inactivation can be obtained using equation (1). Figure 12 shows the first $1200 \mathrm{~s}$ of simulation of the survival behavior of microorganisms subjected to a UV irradiation process in the Taylor-Couette reactor at different angular velocities $(0,600$, and $2000 \mathrm{rpm})$.

For the third bacterial concentration of $30,000,000$ $\mathrm{PFU} \mathrm{mL} \mathrm{m}^{-1}$, five curves of microbial inactivation were obtained in the Taylor-Couette UV disinfection reactor as a 


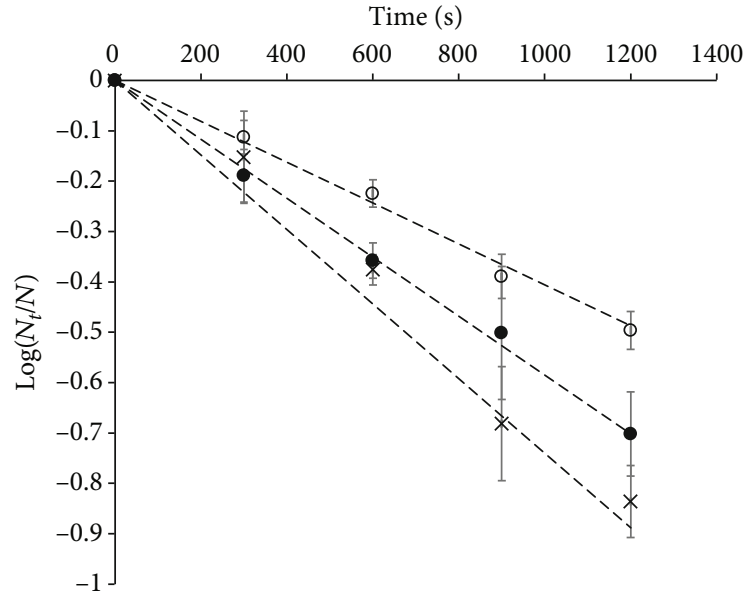

Figure 12: For $400,000 \mathrm{PFU} \mathrm{mL}^{-1}$, experimental data represent the UV microbial inactivation kinetics. The dashed lines represent the first $1200 \mathrm{~s}$ of survival behavior simulation of microorganisms subjected to the UV irradiation process in the Taylor-Couette reactor at different angular velocities: $(\bigcirc) 0 \mathrm{rpm},(\bullet) 600 \mathrm{rpm}$, and (x) $2000 \mathrm{rpm}$.

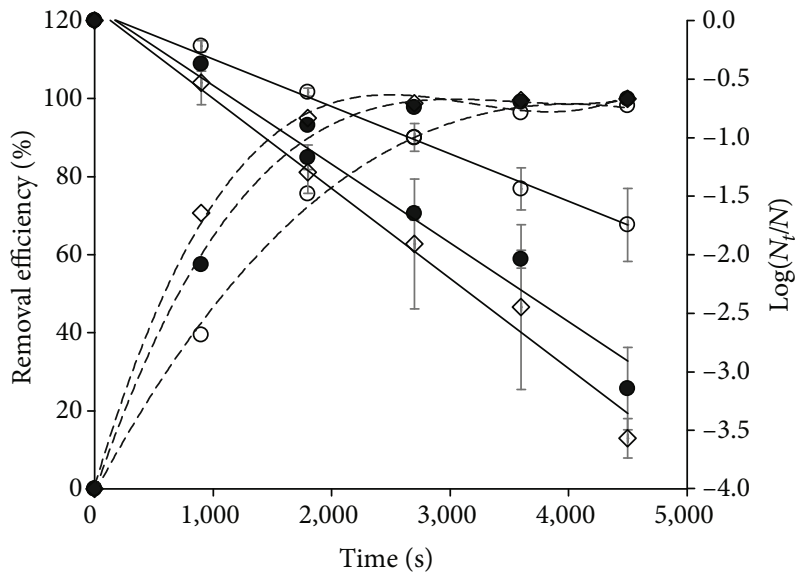

Figure 13: Experimental data are represented by symbols. Lines represent a tendency. For $30,000,000 \mathrm{PFU} \mathrm{mL}^{-1}$, at $0 \mathrm{rpm}$, $k=-4.05 \times 10^{-4} \mathrm{~s}^{-1}$ and the bacteria efficiency removal was $90 \%$ (O). The $k$ value improves gradually by $66 \%$ and $89 \%$ when the angular velocity increases by $300 \mathrm{rpm}(\bullet)$ and $600 \mathrm{rpm}(\diamond)$, respectively. In the same order, the bacteria efficiency removal was $98 \%$ and $100 \%$.

function of the angular velocity. The next set of $k$ values was obtained from each of the following microbial inactivation curves: $0 \mathrm{rpm} \quad\left(k=4.05 \times 10^{-4} \mathrm{~s}^{-1} ; \quad R^{2}=0.9933\right)$, $300 \mathrm{rpm} \quad\left(k=6.73 \times 10^{-4} \mathrm{~s}^{-1} ; R^{2}=0.9756\right)$, and $600 \mathrm{rpm}$ $\left(k=7.68 \times 10^{-4} \mathrm{~s}^{-1} ; R^{2}=0.9870\right)$. It was found that, for both angular velocities of 600 and $1200 \mathrm{rpm}$, the microbial inactivation curves were very similar and only one of them is represented in Figure 13.

In addition, for $2000 \mathrm{rpm}$, the microbial inactivation kinetics does not follow an apparent first-order kinetic equation and was not included in Figure 13). The bacteria exposure time near the UV lamp is a function of the flow

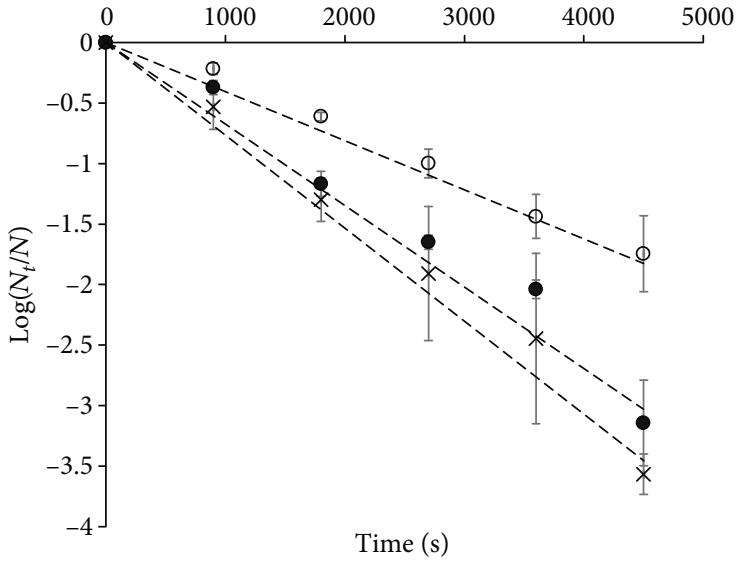

FIgURe 14: For $400,000 \mathrm{PFU} \mathrm{mL}{ }^{-1}$, experimental data represent the UV microbial inactivation kinetics. The dashed lines represent the first $4500 \mathrm{~s}$ of survival behavior simulation of microorganisms subjected to the UV irradiation process in the Taylor-Couette reactor at different angular velocities. The corresponding experimental points are displayed: $(O) 0 \mathrm{rpm},(\bullet) 300 \mathrm{rpm}$, and (×) $600 \mathrm{rpm}$.

pattern (angular velocity) and a random bacteria association to form a clump (getting more important at higher bacteria concentration). Although the cause of the observed deviation is not clear, it is accepted that at short exposure time or subsequent exposure of microorganisms, damage by UV rays to higher fluences can alter the kinetic breakdown of the microorganism $[8,20]$. Therefore, it is likely that at higher angular velocities and a higher bacteria concentration, the bacteria exposure time near the UV lamp was not enough to cause an irreparable damage in the bacteria DNA/RNA. A partial DNA/RNA damage could be repaired. This may be attributed to the observed deviation from the apparent first-order UV disinfection kinetics. Taking as a reference the constant value of the inactivation rate obtained at $0 \mathrm{rpm}$, the inactivation rate constant improves rapidly from $66 \%$ to $89 \%$ when the angular velocity increases by 300 and $600 \mathrm{rpm}$, respectively. From $0 \mathrm{rpm}$ and following the sequence of 300 and $600 \mathrm{rpm}$, the removal of bacterial efficiency in $2700 \mathrm{~s}$ was $90 \%, 98 \%$, and $100 \%$ (Figure 13). For this concentration of bacteria, the inactivation rate constant was correlated with $\omega$ (including the stationary fluid) by the following polynomial equation:

$$
\begin{aligned}
k & =-9.572 \times 10^{-10} \omega^{2}+1.179 \times 10^{-6}(\omega)+4.054 \times 10^{-4} \\
R^{2} & =1.0000 .
\end{aligned}
$$

Figure 14 shows the first $4500 \mathrm{~s}$ of simulation of the survival behavior of microorganisms subjected to a UV irradiation process in the Taylor-Couette reactor at different angular velocities $(0,300$, and $600 \mathrm{rpm})$. The bacterial efficiency removal, subjected to the experimental conditions studied here, was expected to be better at higher concentrations $\left(>\sim 10^{6} \mathrm{PFU} \mathrm{mL}^{-1}\right)$ than at lower concentrations $\left(\sim 10^{4} \mathrm{PFU} \mathrm{mL}^{-1}\right)$. In fact, the number of microorganisms 
TABLE 1: The effect of bacteria concentration and angular velocity on the kinetics of UV microbial inactivation.

\begin{tabular}{lcccc}
\hline$\omega(\mathrm{rpm})$ & $\begin{array}{c}\text { Inactivation rate } \\
\text { constant } k\left(\mathrm{~s}^{-1}\right)\end{array}$ & $R^{2}$ & $\begin{array}{c}\text { Efficiency } \\
\text { removal }(\%)\end{array}$ & $\begin{array}{c}\text { Exposure } \\
\text { time }(\mathrm{s})\end{array}$ \\
\hline $33,000 \mathrm{PFU} \mathrm{mL}^{-1}$ & $4.42 \times 10^{-4}$ & 0.9671 & 63 & 900 \\
0 & $4.91 \times 10^{-4}$ & 0.9833 & 67 & 900 \\
300 & $7.34 \times 10^{-4}$ & 0.9795 & 79 & 900 \\
600 & $8.02 \times 10^{-4}$ & 0.9804 & 83 & 900 \\
2000 & $4.23 \times 10^{-4}$ & 0.995 & 66 & 1200 \\
$400,000 \mathrm{PFU} \mathrm{mL}^{-1}$ & $4.84 \times 10^{-4}$ & 0.988 & 73 & 1200 \\
0 & $5.72 \times 10^{-4}$ & 0.998 & 78 & 1200 \\
300 & $7.19 \times 10^{-4}$ & 0.9580 & 80 & 1200 \\
600 & $7.34 \times 10^{-4}$ & 0.9870 & 83 & 1200 \\
1200 & & & & \\
2000 & $4.05 \times 10^{-4}$ & 0.9933 & 98 & 2700 \\
$30,000,000 \mathrm{PFU} \mathrm{mL}^{-1}$ & 0.9756 & 100 & 2700 \\
0 & $6.73 \times 10^{-4}$ & & 100 & 2700 \\
300 & $7.68 \times 10^{-4}$ & 0.9870 & & \\
600 & & & & \\
\hline & & & & \\
\hline
\end{tabular}

(or a group of them, considered as soluble reacting species) present in the solution is finite. Therefore, the probability that a single microorganism is irreparably damaged by UV irradiation decreases constantly as the treatment progresses. As time passes, there are fewer microorganisms available. Additionally, the bacterial efficiency removal improves as a function of the angular velocity. Table 1 summarizes the effect of the most important parameters (angular velocity and bacteria concentration) on the inactivation rate constant $(k)$.

High $k$ values are always associated to the best experimental conditions. Although under the approach presented in this work, it is not possible to evaluate/predict directly important parameters (such as UV intensity, UV fluence rate, UV fluence received by particles, reflective and diffuse fraction of Pyrex glass walls, and the hydrodynamic pattern) that can accelerate/delay the kinetics of UV microbial inactivation, all these parameters are collected in the inactivation rate constant.

This procedure is less complicated than other approaches [25-27]. In addition, the simulation of the survival behavior of the microorganisms subjected to a UV irradiation process in the Taylor-Couette reactor coincided well with the experimental results.

\section{Conclusions}

It was observed that $E$. coli is not resistant to UV irradiation in discontinuous experiments performed in the reactor in the absence/presence of a Taylor-Couette vortex. Although the formation of counterrotating toroidal vortices within the annular space formed well at $\sim 14 \mathrm{rpm}$, they have no notable impact on the kinetics of microbial inactivation. The improvement in the bacterial efficiency removal starts from $200 \mathrm{rpm}$. The removal of bacterial efficiency is improved depending on both of the following parameters: the angular velocity applied and bacteria concentration. The constant value of the inactivation rate increases between $70 \%$ and $90 \%$ when angular velocity $(600 \mathrm{rpm} \sim 1200 \mathrm{rpm})$ is applied to the Taylor-Couette reactor. Beyond $2000 \mathrm{rpm}$, such improvement begins to decrease. The experimental results (hydrodynamic and kinetic pattern of microbial inactivation) can be correlated with a simple mathematical model to predict the simulation of the survival behavior of E. coli subjected to a UV irradiation process in the Taylor-Couette reactor in a wide range of concentrations of bacteria $\left(10^{4} \sim 10^{6} \mathrm{PFU} \mathrm{mL}^{-1}\right)$ and different angular velocities. This approach would be attractive to biological water treatment designers, since it requires few experiments and minimal physical parameters to define a representative experimental domain of a target water biological treatment.

\section{Data Availability}

The data used to support the findings of this study are included within the article.

\section{Conflicts of Interest}

The authors declare that they have no conflicts of interest.

\section{References}

[1] A. O. Dotson, C. E. Rodriguez, and K. G. Linden, "UV disinfection implementation status in US water treatment plants," Journal-American Water Works Association, vol. 104, no. 5, pp. E318-E324, 2012.

[2] K. Song, M. Mohseni, and F. Taghipour, "Application of ultraviolet light-emitting diodes (UV-LEDs) for water disinfection: a review," Water Research, vol. 94, pp. 341-349, 2016.

[3] J. R. Bolton and K. G. Linden, "Standardization of methods for fluence (UV dose) determination in bench-scale UV experiments," Journal of Environmental Engineering, vol. 129, no. 3, pp. 209-215, 2003.

[4] X. Li, M. Cai, L. Wang, F. Niu, D. Yang, and G. Zhang, "Evaluation survey of microbial disinfection methods in UV-LED water treatment systems," Science of the Total Environment, vol. 659, pp. 1415-1427, 2019.

[5] B. F. Severin, M. T. Suidan, and R. S. Engelbrecht, "Kinetic modeling of U.V. disinfection of water," Water Research, vol. 17, no. 11, pp. 1669-1678, 1983.

[6] J. C. H. Chang, S. F. Ossoff, D. C. Lobe et al., "UV inactivation of pathogenic and indicator microorganisms," Applied and Environmental Microbiology, vol. 49, no. 6, pp. 1361-1365, 1985.

[7] K. M. Pruitt and D. N. Kamau, "Mathematical models of bacterial growth, inhibition and death under combined stress conditions," Journal of Industrial Microbiology, vol. 12, no. 3-5, pp. 221-231, 1993.

[8] W. A. M. Hijnen, E. F. Beerendonk, and G. J. Medema, "Inactivation credit of UV radiation for viruses, bacteria and protozoan (oo)cysts in water: a review," Water Research, vol. 40, no. 1, pp. 3-22, 2006. 
[9] W. Kowalski, Ultraviolet Germicidal Irradiation Handbook, Springer-Verlag, Berlin Heidelberg, 2009.

[10] H. Chick, "An investigation of the laws of disinfection," Journal of Hygiene, vol. 8, no. 1, pp. 92-158, 1908.

[11] X. Y. Zou, Y. L. Lin, B. Xu et al., "Enhanced inactivation of $E$. coli by pulsed UV-LED irradiation during water disinfection," Science of the Total Environment, vol. 650, Part 1, pp. 210-215, 2019.

[12] C. W. Hiatt, "Kinetics of the inactivation of viruses," Bacteriological Reviews, vol. 28, no. 2, pp. 150-163, 1964.

[13] C. Bowker, A. Sain, M. Shatalov, and J. Ducoste, "Microbial UV fluence-response assessment using a novel UV-LED collimated beam system," Water Research, vol. 45, no. 5, pp. 2011-2019, 2011.

[14] W. Z. Tang and M. Sillanpää, "Bacteria sensitivity index of UV disinfection of bacteria with shoulder effect," Journal of Environmental Chemical Engineering, vol. 3, no. 4, pp. 25882596, 2015.

[15] G. D. Harris, V. D. Adams, W. M. Moore, and D. L. Sorensen, "Potassium ferrioxalate as chemical actinometer in ultraviolet reactors," Journal of Environmental Chemical Engineering, vol. 113, no. 3, pp. 612-627, 1987.

[16] M. Sasges and J. Robinson, "Accurate measurement of UV lamp output,” IUVA News, vol. 7, pp. 21-25, 2005.

[17] V. Adam, R. Dreiskemper, and M. Kessler, "Comparison of UV power measurement of low pressure UV-lamps by a worldwide round robin test," IUVA News, vol. 12, pp. 26-29, 2010.

[18] K. G. Lindenauer and J. L. Darby, "Ultraviolet disinfection of wastewater: effect of dose on subsequent photoreactivation," Water Research, vol. 28, no. 4, pp. 805-817, 1994.

[19] K. Oguma, R. Surapong, and J. R. Bolton, "Application of UV light-emitting diodes to adenovirus in water," Journal of Environmental Engineering, vol. 142, no. 3, article 04015082, 2016.

[20] M. A. Würtele, T. Kolbe, M. Lipszc et al., "Application of GaN-based ultraviolet-C light emitting diodes-UV LEDs-for water disinfection," Water Research, vol. 45, no. 3, pp. 1481-1489, 2011.

[21] J. R. Cortelyou, M. A. McWhinnie, M. S. Riddiford, and J. E. Semrad, "The effects of ultraviolet irradiation on large populations of certain water-borne bacteria in motion," Applied Microbiology, vol. 2, no. 4, pp. 227-235, 1954.

[22] D. Schoenen, A. Kolch, and J. Gebel, "Influence of geometrical parameters in different irradiation vessels on UV disinfection rate," International Journal of Hygiene and Environmental Medicine, vol. 194, no. 3, pp. 313-320, 1993.

[23] E. R. Blatchley III, "Numerical modelling of UV intensity: application to collimated-beam reactors and continuous-flow systems," Water Research, vol. 31, no. 9, pp. 2205-2218, 1997.

[24] D. K. Kim, S. J. Kim, and D. H. Kang, "Inactivation modeling of human enteric virus surrogates, MS2, Q $\beta$, and $\Phi$ X174, in water using UVC-LEDs, a novel disinfecting system," Food Research International, vol. 91, pp. 115-123, 2017.

[25] W. Li, M. Li, J. R. Bolton, J. Qu, and Z. Qiang, "Impact of inner-wall reflection on UV reactor performance as evaluated by using computational fluid dynamics: the role of diffuse reflection," Water Research, vol. 109, pp. 382-388, 2017.

[26] A. Kheyrandish, F. Taghipour, and M. Mohseni, "UV-LED radiation modeling and its applications in UV dose determination for water treatment," Journal of Photochemistry and Photobiology A: Chemistry, vol. 352, pp. 113-121, 2018.
[27] K. Chiu, D. A. Lyn, P. Savoye, and E. R. Blatchley III, "Integrated UV disinfection model based on particle tracking," Journal of Environmental Engineering, vol. 125, no. 1, pp. 7-16, 1999.

[28] C. Xu, G. P. Rangaiah, and X. S. Zhaom, “A computational study of the effect of lamp arrangements on the performance of ultraviolet water disinfection reactors," Chemical Engineering Science, vol. 122, pp. 299-306, 2015.

[29] T. Sultan, "Numerical study of the effects of lamp configuration and reactor wall roughness in an open channel water disinfection UV reactor," Chemosphere, vol. 155, pp. 170-179, 2016.

[30] D. Liu, C. Wu, K. Linden, and J. Ducoste, "Numerical simulation of UV disinfection reactors: evaluation of alternative turbulence models," Applied Mathematical Modelling, vol. 31, no. 9, pp. 1753-1769, 2007.

[31] B. A. Wols, J. A. M. H. Hofman, E. F. Beerendonk, W. S. J. Uijttewaal, and J. C. van Dijk, "A systematic approach for the design of UV reactors using computational fluid dynamics," AICHE Journal, vol. 57, no. 1, pp. 193-207, 2011.

[32] J. Chen, B. Deng, and C. N. Kim, "Computational fluid dynamics (CFD) modeling of UV disinfection in a closedconduit reactor," Chemical Engineering Science, vol. 66, no. 21, pp. 4983-4990, 2011.

[33] C. Xu, X. S. Zhao, and G. P. Rangaiah, "Performance analysis of ultraviolet water disinfection reactors using computational fluid dynamics simulation," Chemical Engineering Journal, vol. 221, pp. 398-406, 2013.

[34] L. Vázquez, A. Alvarez-Gallegos, F. Z. Sierra, C. Ponce de León, and F. C. Walsh, "Simulation of velocity profiles in a laboratory electrolyser using computational fluid dynamics," Electrochimica Acta, vol. 55, no. 10, pp. 3437-3445, 2010.

[35] D. A. Lyn, K. Chiu, and E. R. Blatchley III, "Numerical modeling of flow and disinfection in UV disinfection channels," Journal Environmental Engineering, vol. 125, no. 1, pp. 17-26, 1999.

[36] B. A. Wols and C. H. M. Hofman-Caris, "Modelling micropollutant degradation in $\mathrm{UV} / \mathrm{H}_{2} \mathrm{O}_{2}$ systems: Lagrangian versus Eulerian method," Chemical Engineering Journal, vol. 210, pp. 289-297, 2012.

[37] C. Díaz-Flores, M. L. Alvarez, S. Silva-Martínez, and A. Alvarez-Gallegos, "Prediction of the indirect advanced oxidation of acid orange 7 using a 3D RVC cathode for $\mathrm{H}_{2} \mathrm{O}_{2}$ production in a divided electrochemical reactor," International Journal of Green Technology, vol. 1, pp. 1320, 2015.

[38] B. Ramírez, V. Rondán, L. Ortiz-Hernández, S. Silva-Martínez, and A. Alvarez-Gallegos, "Semi-empirical chemical model for indirect advanced oxidation of Acid Orange 7 using an unmodified carbon fabric cathode for $\mathrm{H}_{2} \mathrm{O}_{2}$ production in an electrochemical reactor," Journal of Environmental Management, vol. 171, pp. 29-34, 2016.

[39] A. Alvarez-Gallegos and S. Silva-Martınez, "Modeling of electro-Fenton process," in Electro-Fenton Process, M. Zhou, M. Oturan, and I. Sirés, Eds., vol. 61 of The Handbook of Environmental Chemistry, Springer, Singapore, 2017.

[40] N. Ohmura, K. Kataoka, Y. Shibata, and T. Makino, "Effective mass diffusion over cell boundaries in a Taylor-Couette flow system," Chemical Engineering Science, vol. 52, no. 11, pp. 1757-1765, 1997. 
[41] K. Kataoka, H. Doi, T. Hongo, and M. Futagawa, "Ideal plugflow properties of Taylor vortex flow," Journal of Chemical Engineering of Japan, vol. 8, no. 6, pp. 472-476, 1975.

[42] S. Cohen and D. M. Marom, "Experimental and theoretical study of a rotating annular flow reactor," The Chemical Engineering Journal, vol. 27, no. 2, pp. 87-97, 1983.

[43] T. K. Sengupta, M. F. Kabir, and A. K. Ray, "A Taylor vortex photocatalytic reactor for water purification," Industrial and Engineering Chemistry Research, vol. 40, no. 23, pp. 5268$5281,2001$. 